\title{
Regenerative Braking-Methods to Efficiently Use Regenerated Energy
}

\section{Priya Sharma*}

M.Tech, G.H Raisoni College of Engineering, Nagpur, India

\begin{abstract}
One of the important factors of planned urbanization is a sustainable mass urban transport. All most every metro have chosen Metro Rail has the mass urban rail transport. Electricity has always been the main source of energy for urban metro transport as it has all the qualities required for mass urban transport system. Different electric systems have been used world over to supply the electricity used for Mass urban rail transport systems, popularly known as the Traction energy requirement. In this paper the traction energy supplied using $750 \mathrm{~V} D C$ is being dealt with. In majority of the metro rail systems, the rolling stock is equipped with regenerative brakings. In the regenerative braking the electric motor can act as a generator recovering the vehicles kinetic energy and converting it into electric energy. In metro rail since the distance between the stations is generally around $1 \mathrm{~km}$, so the frequency of the braking is high so this method can be efficiently used. This highlights the different methods that be used for efficiently using the regenerated power in an a $750 \mathrm{~V}$ Dc traction system.
\end{abstract}

Keywords: Regeneration; Braking; Metro rail; Green energy

\section{Introduction}

There has been a continuous effort in reducing the power consumption in traction system by using various Methods. In a conventional braking system, the energy is dissipated as heat in the braking resistors. In a regenerative braking system the kinetic energy is converted to electric energy by the same traction motor which acts as a generator while braking. A part of this regenerated energy is used by other trains which are in the power mode (Figure 1). This reduces the consumption of net grid electrical energy required for powering trains there by conserving electrical energy and also reducing the energy bills. The advantage of using regenerative braking is that unlike the normal braking system there is no heat generated and this will in turn reduce the heat produced in Underground section of the Metro Rail route. The best ways to use the regenerated power is to feed it back to auxiliary power requirement and also to powering trains. This paper deals with the various technologies that can be used for effective utilization of regenerative energy and also the advantageous it will give to the system [1].

\section{Regenerative Energy}

Till recently the regenerative power generated during the braking was utilized by the powering trains in the same route. This is known as receptivity and is affected by a number of variables, including location, traffic density and line voltage if there are no powering trains the generated power is dissipated as heat. So if the service frequency is less then, the utilization of regenerated power can drop to even $5 \%$ (Figure 1). In general the regenerated energy in a metro is $45-47 \%$ of motoring power and about $20 \%$ of this is consumed in traction system

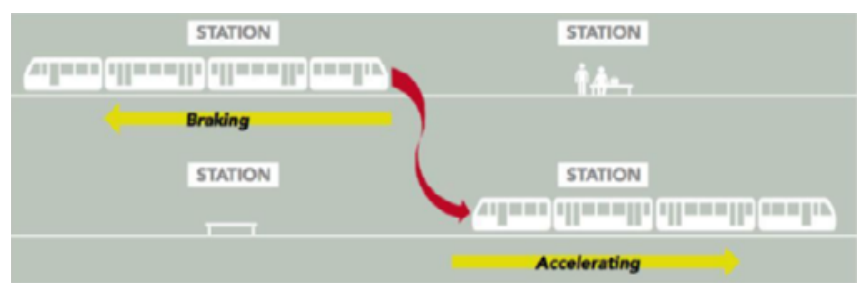

Figure 1: Regenerated energy which is used by other trains which are in the power mode.

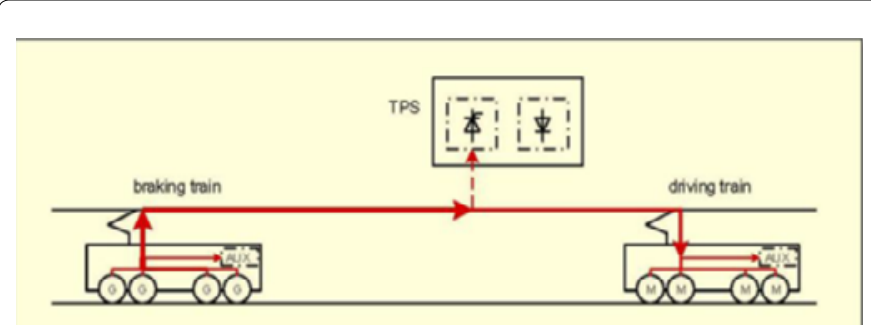

Figure 2: Braking current flow and distribution in a DC traction power supply.

the other 20-27\% increases the DC line bus voltage. Studies have shown that regeneration technologies could potentially reduce the energy consumption of urban rail between $10 \%$ and $45 \%$, depending on the track gradients and the service characteristic [2].

\section{Methods to recover regenerated energy}

Two systems have developed over the years to utilize the regenerated energy from the Rolling Stock

1. Energy conversion system by converting the DC power to AC power through inverters

\section{Energy Storage system.}

\section{Inverters}

Figure 2 summarizes the braking current flow and distribution in a DC traction power supply with inverters in Traction Power Supply system (without rheostatic brake). Primarily the load on DC side will be supplied, In case of excess energy the energy will be converted and

*Corresponding author: Priya Sharma, M.Tech, G.HRaisoni College of Engineering Nagpur, India, Tel: +91- 98817 13131; E-mail: tppriyasharma@yahoo.co.in

Received March 10, 2015; Accepted May 26, 2015; Published June 15, 2015

Citation: Sharma P (2015) Regenerative Braking-Methods to Efficiently Use Regenerated Energy. J Electr Electron Syst 4: 146. doi:10.4172/23320796.1000146

Copyright: (c) 2015 Sharma P. This is an open-access article distributed under the terms of the Creative Commons Attribution License, which permits unrestricted use, distribution, and reproduction in any medium, provided the original author and source are credited. 
re-generated to the 3-phase AC grid. During regeneration, the inverter system pumps the surplus energy back into the AC source, this surplus energy can be utilized for the station loads (Figure 3) and can even be fed back to the grid and the inverter works as an active power filter in normal traction.

During regeneration, the inverter system pumps the surplus energy back into the AC source, this surplus energy can be utilized for the station loads (Figure 3) and can even be fed back to the grid and the inverter works as an active power filter in normal traction.

\section{Advantages:}

1. Can be installed on new and old substations

2. Low maintenance costs and easy control

3. Improves quality of power

4. Can be used by all vehicles on the line

5. Energy efficient due to fewer transformation losses than in storage applications

6. Potential downsizing of the line side braking resistors

7. Lower safety constraints in comparison with onboard systems

8. Implementation, maintenance and repair do not affect operations

\section{Disadvantageous}

Fine tuned analysis for choosing the right locations

1. Place availability in the substations or along the line

2. No reduction in number of traction sub stations

\section{Energy Storage Systems (ESS)}

There are presently three types of ESS that are in use

\section{Flywheels (FESS)}

Fly wheel has the simplest design of all the three ESS. Energy is stored as kinetic energy using a rotor that rotates at high angular speed.

$$
E=1 / 2 J \omega^{2}
$$

Where $\mathrm{j}$ is the moment of inertia and $\mathrm{w}$ is the angular velocity. The rotor is a hollow cylinder and has magnetic bearings to minimize the friction. The rotor is located in a vacuum pipe to decrease the friction even more. The rotor is integrated into a capacity depends on the mass and shape of the rotor and on the maximum available angular velocity.

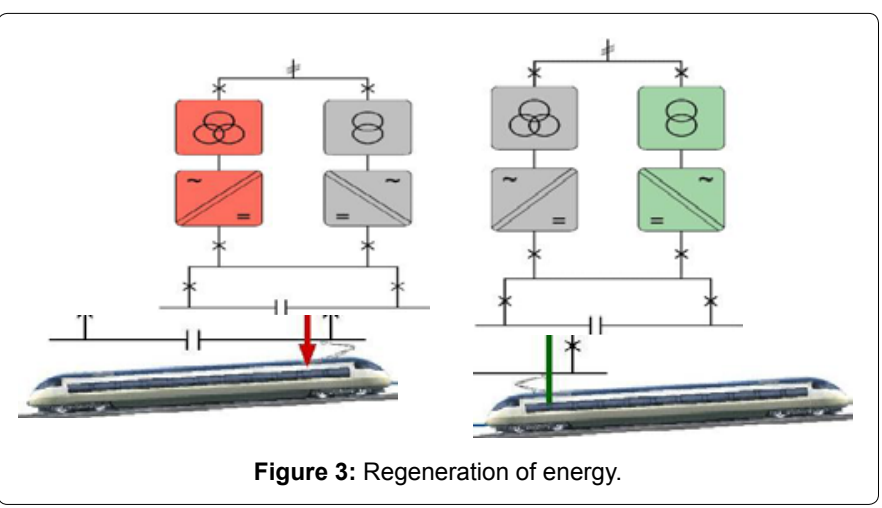

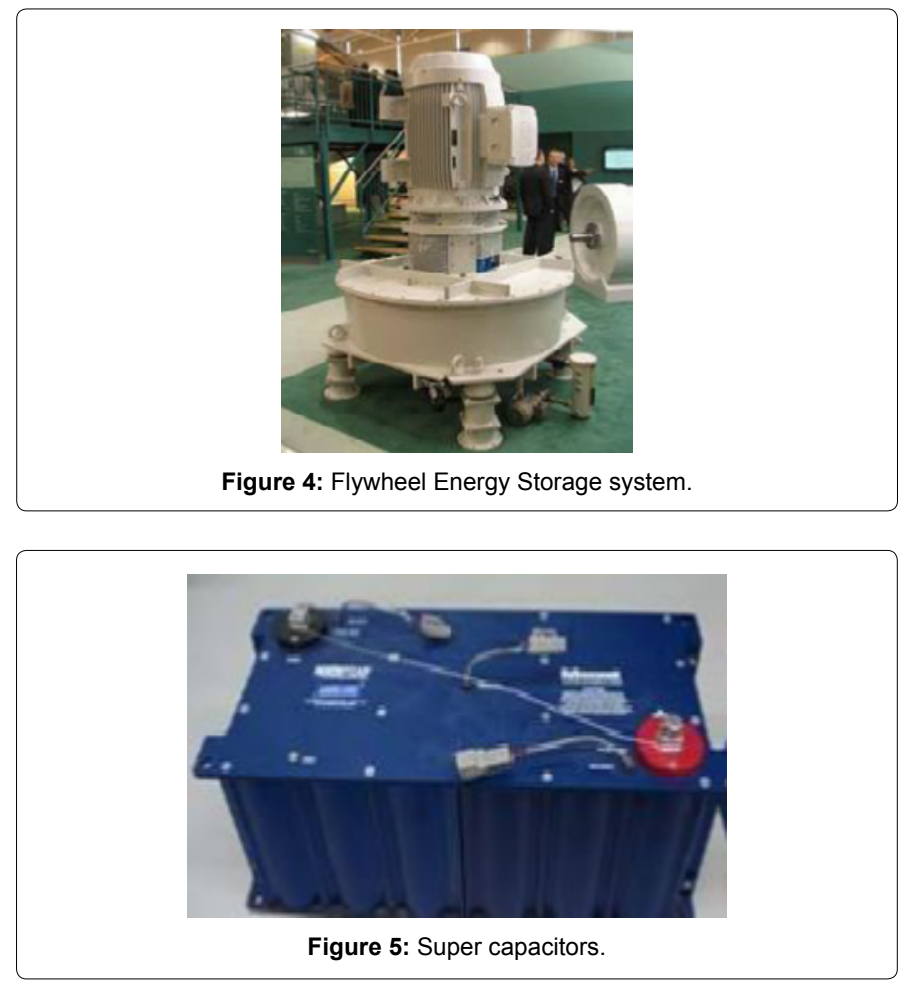

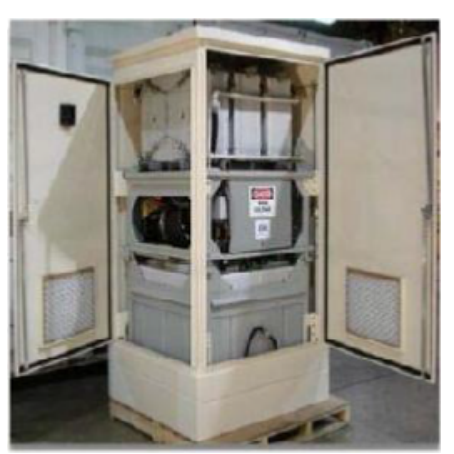

Figure 6: Battery storage system.

FESS also has limitations. FESS has a higher cost per kWH than commodity batteries. The FESS design must resolve safety concerns about energy containment in case of flywheel or bearing failure. Since FESS is a mechanical device, it is more susceptible to moving part failures than super capacitors or batteries. Finally, some FESS designs present a greater challenge to achieve effective cooling at reasonable cost (Figure 4).

\section{Supercapacitors (SESS)}

Super capacitors (Figure 5) store charge in similar way to conventional capacitors, but the charge does not accumulate in two conductors, but in the interface between the surface of a conductor and an electrolyte solution. It consists of two electrodes consist of two electrodes which allow a potential to be applied across the cell, therefore they present two double layers, on each at electrode/ electrolyte interface. The principle of super capacitors characteristic that makes it suitable for EES, is the possibility of charge and discharge without lost of efficiency for thousands of cycles. This is because they store electrical energy directly. Super capacitors can recharge in 
a very short time having a great facility to supply high and frequent power demand peaks. However, SESS has higher cost per kWH than battery ESS (BESS) or flywheel ESS (FESS). SESS contains dielectric fluids which are typically both toxic and flammable [3]. This presents a considerable burden for Transit Operators, who strongly prefer to minimize materials and equipment risks. Hazardous failure modes occur if the capacitors are subject to an overvoltage.

\section{Batteries (BESS)}

These systems could be located in any place (Figure 6). Batteries store energy in a reversible chemical reaction. Batteries have stored and delivered energy since the first electrical devices were discovered, and have shown continued if slow advances in characteristics and performance in each decade and generation. A DC to DC converter regulates the flow of energy into and out of the BESS. The outstanding advances in both power electronics and energy storage technologies have permitted ESSs to become a very promising option to manage regenerated braking energy in urban rail. ESSs can be installed either on board vehicles or at specific points along the track. The former option enables rail vehicles to temporarily store their own braking energy and reuse it for subsequent acceleration. In turn, stationary ESSs accumulate energy from any braking train nearby and release it when a power demand is detected.

\section{Conclusion}

With an extensive and expanding rail transit network, energy efficiency will always be an important component of environmental impact and operation costs. The three methods described in this paper describe the technology that can be adapted for that purpose. This not only reduces the operations cost but also improve the "Green points" of the system. The receptivity of the network is also improved.

\section{Referencess}

1. WP2B Energy Recovery -An overview of braking energy recovery technologies in the public transport field. The "Ticket to Kyoto".

2. Brochure of Inverters Secheron.

3. Guerrero MA, Romero E, Barrero F, Milanes MI, Gonzalez E (2012) Supercapacitors: Alternative Energy Storage system by, Power electronics and electric syatems, school of Indistrial Engineering ( University of Extremadura). 